\title{
COMUNICAÇÃO
}

\section{OCORRÊNCIA DE Listeria spp. EMAMOSTRAS DE CARNE BOVINA MOÍDA COMERCIALIZADAS NO MUNICÍPIO DE NITERÓI, RJ, BRASIL}

\author{
Occurrence of Listeria spp. in bovine ground meat samples \\ commercialized in Niterói, RJ, Brazil \\ Samira Pirola Santos Mantilla1, Robson Maia Franco² ${ }^{2}$ Luiz Antônio Trindade Oliveira², \\ Érica Barbosa Santos ${ }^{3}$, Raquel Gouvêa ${ }^{4}$
}

\begin{abstract}
RESUMO
Foram analisadas 30 amostras de carne bovina moída resfriada, previamente embaladas, provenientes de estabelecimentos comercias do município de Niterói, RJ, com o objetivo de se observar a frequiência de bactérias do gênero Listeria spp. Utilizou-se para isto a metodologia revisada do USDA. 50\% das amostras analisadas apresentaram contaminação por Listeria spp., sendo a $L$. innocua (SEELIGER \& SCHOOFS, 1979) a espécie isolada em maior número, seguida pela L. monocytogenes (MURRAY et al., 1926; PIRIE, 1940). Na tipificação sorológica, observou-se maior prevalência de L. monocytogenes pertencente ao sorotipo 4b (50\%), porém o sorotipo $1 / 2 \mathrm{c}$ também foi identificado. As amostras que apresentaram-se contaminadas com L. monocytogenes, caracterizam-se como potencialmente capazes de ocasionar enfermidades transmitidas por alimentos.
\end{abstract}

Termos para indexação: Microbiologia, carne vermelha, listeriose.

\section{ABSTRACT}

Thirty bovine ground meat samples from several markets from Niterói, RJ, were analyzed, in order to observe the frequency of bacterias of the genus Listeria spp. A USDA revised methodology as applied in this research. Fifty percent of the samples were contaminated by Listeria spp.. L. innocua species as the most isolated, followed by L. monocytogenes. In serological typification, the greatest prevalence was that of sorotype $4 \mathrm{~b}$ L. monocytogenes $(50 \%)$, however the $1 / 2 \mathrm{c}$ sorotype was also identified. Samples contaminated by L. monocytogenes are potentially capable of causing diseases through food consumption.

Index terms: Microbiology, red meat, listeriosis.

\section{(Recebido em 17 de outubro de 2006 e aprovado em 13 de março de 2007)}

A carne moída bovina é um alimento que, além de possuir maior área de superfície e de ser altamente manuseado, possibilitando o crescimento bacteriano, permite o desenvolvimento de bactérias psicrotróficas patogênicas como L. monocytogenes, por permanecerem estocados sob temperatura de refrigeração até o consumo. A L. monocytogenes é um patógeno emergente capaz de ocasionar meningite e provocar abortos através da ingestão de alimentos contaminados, isto é aqueles que não foram submetidos ao tratamento térmico adequado.

As listerias são bastonetes Gram positivos, não produtoras de esporo e não ácido resistente que antigamente foram denominadas como Listerella. A denominação do gênero foi mudada em 1940 para Listeria. Em certo momento, acreditou-se que as listerias estivessem relacionadas a bactérias corineformes e, de fato, foram colocadas na família Corinebacteriaceae. Contudo, atualmente, está claro que estão mais relacionadas a Bacillus spp., Lactobacillus spp., e Streptococcus spp. (JAY, 2005).

O gênero Listeria é classificado juntamente com os gêneros Lactobacillus, Erysipelotrix, Brochothrix, Caryophanon e Renibacterium. As espécies reconhecidas são: L. monocytogenes, L. ivanovii, L. innocua, $L$. welshimeri, L. seeligeri, L. grayi, L. murrayi. A espécie $L$. denitrificans foi transferida para o gênero Jonesia. No que diz respeito à sorologia, foram descritos 16 sorovares, sendo 15 antígenos somáticos "O" e cinco antígenos flagelares "H". A Listeria monocytogenes (MURRAY et al., 1926; PIRIE, 1940), considerada a espécie patogênica para homens e animais, contém os sorovares $1 / 2 \mathrm{a}, 1 / 2 \mathrm{~b}, 1 /$ 2c, 3a, 3b, 3c, 4a, 4b, 4c, 4e, 7 (SEELIGER \& JONES, 1996).

\footnotetext{
'Mestre - Departamento de Tecnologia de Alimentos - Universidade Federal Fluminense/UFF - Rua Vital Brazil Filho, 64, Santa Rosa - 24230-340 Niterói, RJ - samiramantilla@yahoo.com.br

2Doutores, Professores - Departamento de Tecnologia de Alimentos - Universidade Federal Fluminense/UFF - Rua Vital Brazil Filho, 64, Santa Rosa 2Doutores, Professores - Departamento de Tecnologia de Alimentos - Univ
$-24230-340$ - Niterói, RJ - robsonmf@vm.uff.br, proflato@vm.uff.br

${ }^{3}$ Pós-Graduanda - Departamento de Tecnologia de Alimentos - Universidade Federal Fluminense/UFF - Rua Vital Brazil Filho, 64, Santa Rosa - 24230-340 Niterói, RJ - ericaebs@hotmail.com

${ }^{4}$ Médica Veterinária - Departamento de Tecnologia de Alimentos - Universidade Federal Fluminense/UFF - Rua Vital Brazil Filho, 64, Santa Rosa 24230-340 - Niterói, RJ - quelgouvea@yahoo.com.br
} 
A classificação sorológica exige tipagem dos antígenos $\mathrm{O}$ e $\mathrm{H}$, efetuada em laboratórios de referência. É utilizada, basicamente, para estudos epidemiológicos. Os sorotipos $1 \mathrm{a}, 1 \mathrm{~b}$ e $4 \mathrm{~b}$ constituem mais de $90 \%$ dos microrganismos isolados em seres humanos. Constatouse que o sorotipo $4 \mathrm{~b}$ provocou uma epidemia de listeriose associada a queijo feito com leite, inadequadamente pasteurizado (JAWETZ et al., 1998).

Segundo Jay (2005), a grande heterogeneidade antigênica da $L$. monocytogenes pode estar relacionada com o grande número de hospedeiros animais nos quais é capaz de multiplicar-se. Em geral, linhagens 4b são mais freqüentemente associadas com surtos, enquanto linhagens $1 / 2$ são mais relacionadas com produtos alimentícios.

A L. monocytogenes é um patógeno intracelular facultativo, que pode crescer em macrófagos, células epitelias e fibroblastos cultivados. Todas as cepas virulentas produzem uma hemolisina, a listeriolisina $\mathrm{O}$, que está geneticamente relacionada com a estreptomicina $\mathrm{O}$ e a pneumolisina (MURRAY et al., 2000).

O primeiro caso de listeriose humana foi denunciado em 1929, e desde então está comprovado que esta enfermidade apresenta-se esporadicamente, em todo o mundo. L. monocytogenes é o agente etiológico de aproximadamente $98 \%$ dos casos que ocorrem em pessoas e $85 \%$ dos casos que ocorrem nos animais. Pelo menos três casos de enfermidade em pessoas foram causados por L. ivanovii (Seeliger, Rocourt, Schrettenbrunner, Jones, 1984) (SEELIGER, 1984), e somente um por L. seeligeri (ROCOURT \& GRIMONT, 1983).

A ampla distribuição de Listeria spp. na natureza e nas fezes dos animais explica que sua presença em carnes cruas é quase inevitável, podendo variar de zero a $68 \%$. A carne suína é a mais contaminada, porém, também é freqüente a contaminação de carne crua de aves. Existe pouca informação sobre a virulência das cepas de $L$. monocytogenes isoladas de carnes (JOHNSON et al., 1992 citados por ACHA \& SZYERES, 2001).

A morbidade da listeriose é variável com a espécie, podendo apresentar-se como doença individual esporádica ou como surto epidêmico, com casos endêmicos. A letalidade também é variável, ficando geralmente entre 20-

\footnotetext{
${ }^{5}$ JOHNSON, J. L.; DOYLE, M. P.; CASSENS, R. G. Listeria monocytogenes and other Listeria spp. in meat and meat products: a review. Journal Food Protect, Oxford, v. 53, p. 81-91, 1990.
}

50\% (CORRÊA \& CORRÊA, 1992). A incidência da doença é baixa, porém, é uma enfermidade importante por sua alta letalidade (ACHA \& SZYERES, 2001).

A transmissão da Listeria spp. pode ocorrer tanto por contato direto quanto indireto com fontes contaminadas; por via oral, ocular, cutânea, respiratória e urogenital. O organismo pode estar presente em secreções oculares, nasal e purulenta da epiderme e na urina, em placenta de bovino infectado; em outros tecidos contaminados, fezes e sangue. Porém, a transmissão por alimentos parece ser a forma mais importante (MARTH, 1988; SILVA, 1996).

Listeria spp. vem sendo isolada de uma grande variedade de fontes, e em muitas situações; $L$. innocua é mais comumente encontrada do que $L$. monocytogenes, conforme descrevem os pesquisadores: Lund et al. (1991), Petran \& Swanson (1993), Sireli \& Erol (1999) e Yucel et al. (2004).

Os autores Kamat \& Nair (1996) e Petran \& Swanson (1993) realizaram experimentações "in vitro", com o intuito de relacionar a presença de $L$. innocua com a de $L$. monocytogenes e tentar explicar o porquê da maior freqüência de isolamento de L. innocua, nos alimentos.

Objetivou-se, neste experimento, analisar a ocorrência de bactérias do gênero Listeria em carnes bovinas moídas cruas, previamente embaladas e resfriadas, comercializadas no município de Niterói, RJ.

Foram obtidas 30 amostras de carne bovina moída embalada e resfriada em estabelecimentos comerciais, incluindo supermercados e açougues, em áreas de diferentes níveis sociais do município de Niterói, RJ. As análises bacteriológicas foram realizadas no Laboratório de Controle Microbiológico de Produtos de Origem Animal da Faculdade de Veterinária da Universidade Federal Fluminense (UFF), onde foram realizados o isolamento, a identificação bioquímica das bactérias do gênero Listeria e o teste de sensibilidade aos antimicrobianos. A identificação sorológica das cepas de Listeria spp. isoladas foi feita na Fundação Oswaldo Cruz (FIOCRUZ).

A técnica utilizada foi baseada na metodologia revisada do "USDA-FSIS", segundo McClain \& Lee (1984), que inclui um enriquecimento primário, enriquecimento secundário e plaqueamento, com uso de três meios : "Lithium Chloride Phenylethanol Moxalactam Agar" (LPM), "Modified McBride Agar" (MMA) e "Modified Oxford Agar" (MOX)

No enriquecimento primário utilizou-se o "UVM Modified Listeria Enrichment Broth", denominado caldo de enriquecimento primário (LEB 1), no volume de $225 \mathrm{~mL}$, homogeneizado com 25 g da amostra no "stomacher", durante dois minutos. A incubação foi a $30^{\circ} \mathrm{C}$, por 24 horas. 
Após a incubação, uma alíquota de 1,0 mL do LEB 1 foi transferida para o tubo contendo $4,5 \mathrm{~mL}$ de solução de hidróxido de potássio $(\mathrm{KOH})$ a $0,25 \%$. Este foi homogeneizado por um minuto e, partindo desta suspensão, foram semeadas placas contendo ágar LPM, MMA e MOX. Outras placas, contendo estes meios de cultura, foram semeadas diretamente com o LEB 1. Todas as placas foram incubadas a $30^{\circ} \mathrm{C}$, por 24 a 48 horas.

Após a incubação do caldo de enriquecimento primário, uma alíquota de $0,1 \mathrm{~mL}$ do LEB 1 foi transferida para o tubo, contendo $10 \mathrm{~mL}$ de Caldo Fraser, suplementado com "Fraser Selective Supplement", que contém ácido nalidíxico $(10 \mathrm{mg})$, acriflavina $(12,5 \mathrm{mg})$ e citrato férrico amoniacal $(250 \mathrm{mg})$, sendo incubado a $30^{\circ} \mathrm{C}$, por 24 horas. Após este período, também foi realizado o plaqueamento direto e indireto, com prévia passagem pela solução de $\mathrm{KOH}$, nos mesmos meios de cultura citados.

As colônias típicas, isoladas do plaqueamento do enriquecimento primário e secundário, foram semeadas em placas, contendo ágar Tripticase de soja com $0,6 \%$ de Extrato de Levedura. Estas placas foram incubadas a $30^{\circ} \mathrm{C}$, durante $24 \mathrm{~h}$ e, após este período, as colônias crescidas foram observadas em microscópio estereoscópio para a certificação de sua pureza.

Foi realizado o diagnóstico presuntivo para Listeria spp. através das seguintes provas bioquímicas: catalase (+); motilidade , onde o crescimento em forma de "guardachuva" caracterizou a prova como positiva; e esfregaço em lâmina, corado pelo método de Gram (bastonetes pequenos e curtos, em cadeias curtas, paralelamente ou em forma de "V", Gram positivos).

As cepas características foram submetidas às provas bioquímicas, baseadas no esquema proposto por McClain \& Lee (1984), para a identificação da espécie, a saber : comportamento em ágar tríplice açúcar ferro; redução do nitrato a nitrito; produção da uréase; prova do vermelho de metila; prova de Voges-Proskauer; fermentação de carboidratos (xilose, ramnose, manitol, maltose e glicose); prova da hidrólise da esculina; teste de hemólise e "Camptest".

O processo de caracterização antigênica das cepas isoladas de L. monocytogenes foi realizado no Laboratório de Zoonoses Bacterianas do Departamento de Bacteriologia do Instituto Oswaldo Cruz, Fundação Oswaldo Cruz. A técnica baseou-se na aglutinação com antígenos "O" e "H", conforme recomendações do Donker-Voet (1959) e Seeliger \& Höhne (1979).

Das 30 amostras de carnes moídas analisadas, 15 (50\%) apresentaram contaminação por Listeria spp., sendo duas $(6,7 \%)$ positivas para L. monocytogenes. Ao total, foram isoladas 83 cepas de Listeria spp., sendo $6 \mathrm{~L}$. monocytogenes e 77 L. innocua. A relação do número de cepas dos diferentes sorotipos isolados está disposta na TABELA 1.

Os resultados obtidos são compatíveis com os de Vitas et al. (2004) que encontraram, no Norte da Espanha, $62,3 \%$ das amostras de carne moída bovina e suína contaminadas com Listeria spp. Entretanto, no trabalho realizado por Sireli \& Erol (1999), em Ankara, a incidência de Listeria spp., nas amostras de carne bovina moída foi de $97 \%$. Yucel et al. (2005) também evidenciaram uma maior ocorrência de Listeria spp. em amostras de carne bovina moída crua $(86,4 \%)$.

Neste experimento, somente duas amostras $(6,7 \%)$, das 30 analisadas, apresentaram-se contaminadas com $L$. monocytogenes. Yucel et al. (2005) também relataram uma baixa ocorrência desta espécie em carnes bovinas, moídas e inteiras, e carne de frango, onde somente $6,16 \%$ das amostras demonstraram-se contaminadas. Samadpour et al. (2006) observaram um número menor ainda de carnes moídas contaminadas com L. monocytogenes $(3,5 \%$ das amostras analisadas). Em contrapartida, no trabalho desenvolvido por Mena et al. (2004), das 17 amostras de carne bovina crua, três $(17,7 \%)$ foram positivas para $L$.

TABELA 1 - Sorotipos de Listeria spp., isolados das amostras de carne moída.

\begin{tabular}{|c|c|c|c|c|c|}
\hline Espécies & Sorotipos & $\mathbf{N}^{\circ}$ de cepas & $(\%)$ & Totc & $(\%)$ \\
\hline \multirow[t]{3}{*}{ L. innocua } & $6 a$ & 66 & $(85,7)$ & \multirow{3}{*}{77} & \multirow{3}{*}{$(92,8)$} \\
\hline & $6 b$ & 7 & $(9,1)$ & & \\
\hline & Não tipável & 4 & $(5,2)$ & & \\
\hline \multirow[t]{2}{*}{ L. monocytogenes } & $4 \mathrm{~b}$ & 3 & $(50)$ & \multirow[t]{2}{*}{6} & \multirow[t]{2}{*}{$(7,23)$} \\
\hline & $1 / 2 \mathrm{C}$ & 3 & $(50)$ & & \\
\hline Total & & 83 & & 83 & \\
\hline
\end{tabular}


monocytogenes, demonstrando uma maior ocorrência desta espécie bacteriana neste alimento. Os resultados de Vitas et al. (2004) são similares aos de Mena et al. (2004), visto que estes pesquisadores também encontraram $L$. monocytogenes em grande parte das amostras analisadas (34,9\%).

Em relação ao número de cepas de $L$. monocytogenes isoladas, detectaram-se seis cepas $(7,23 \%)$ nas amostras testadas. Resultados semelhantes foram encontrados por Fantelli \& Stephan (2001), os quais encontraram somente $10,75 \%$ desta espécie em carnes moídas bovinas e suínas, e por Yucel et al. (2004), que isolaram $8,25 \%$ de L. monocytogenes a partir de carne bovina, moída e inteira, e de carne de frango. No entanto, Sireli \& Erol (1999) isolaram um maior número de $L$. monocytogenes de carnes bovinas moídas (28\%). Kasnowski (2004) também encontrou um alto percentual (30,1\%) de cepas de L. monocytogenes em carnes bovinas,inteiras e moídas.

A maior ocorrência de L. innocua, comparando-se com a L. monocytogenes em produtos alimentícios, vem sendo relatada por muitos pesquisadores. Neste trabalho, somente duas espécies do gênero Listeria foram detectadas: L. innocua, isolada em maior percentagem (92,8\%), e L. monocytogenes (7,23\%). Yucel et al. (2004) obtiveram resultados similares, isolando $90 \%$ de $L$. innocua em carnes bovinas (moídas e inteiras) e de frango. Sireli \& Erol (1999) também encontraram elevada ocorrência de $L$. innocua $(92 \%)$ em carne moída, seguida pela $L$. monocytogenes $(28 \%)$ e por outras espécies do gênero Listeria (24\%). Os resultados de Kasnowski (2004) também corroboram os resultados observados neste experimento, visto que isolou $70 \%$ de L. innocua a partir de carnes bovinas inteiras e moídas. Yucel et al. (2005) também isolaram L. innocua em maior quantidade de amostras (46,57\%) comparando-se com L. monocytogenes, que foi isolada em apenas $6,16 \%$ das amostras de carne bovina e de frango analisadas.

De acordo com Kamat \& Nair (1996), L. innocua pode ser um organismo ideal e seguro como um marcador de L. monocytogenes em indústrias alimentícias, visto que este exibe a maioria das características da L. monocytogenes, com exceção da não produção de hemolisina e da apatogenicidade. Estes pesquisadores demonstraram uma resposta comparativa entre as duas espécies de Listeria, em caldo BHI ou em carne homogeneizada, aos seguintes tratamentos: calor; irradiação; ácido lático; e nitrato de sódio. Isto possibilita o uso de L. innocua como um indicador biológico para verificar a eficiência destes tratamentos, efetuados durante o processamento de produtos cárneos.
Petran \& Swanson (1993) estudaram o crescimento de três cepas de L. monocytogenes, inoculadas simultaneamente com L. innocua em amostras de queijo, e nos seguintes meios de cultura: Caldo Fraser; Caldo Tripticase de soja com 0,6\% de Extrato de levedura (CTS); e Caldo UVM. O crescimento das duas espécies bacterianas foi similar no CTS e nas amostras de queijo inoculadas. Porém, no Caldo Fraser e no Caldo UVM, a população de $L$. innocua foi significativamente maior do que a de $L$. monocytogenes. Isto ocorreu quando o meio era inoculado, individualmente ou simultaneamente, com as duas espécies. Este fato explica, em parte, porque L. innocua é isolada mais freqüentemente de alimentos do que $L$. monocytogenes.

De acordo com Jay (2005) o sorotipo 4 b da $L$. monocytogenes é o mais envolvido com surtos de listeriose alimentar. Nesta pesquisa, a tipificação sorológica das cepas de L. monocytogenes isoladas pertenciam aos sorogrupos: 4b (50\%), seguida pelo sorotipo $1 / 2 \mathrm{c}(50 \%)$. Kasnowski (2004) obteve resultados semelhantes, isolando $86,5 \%$ das cepas de $L$. monocytogenes, oriundas de carne bovina, pertencentes ao sorotipo $4 \mathrm{~b}$ e $13,5 \%$ do sorotipo $1 / 2 b$.

Em contrapartida, Vitas et al. (2004) ao analisarem 103 amostras de carnes vermelhas positivas para $L$. monocytogenes em Navarra, observaram que $78,1 \%$ das cepas isoladas pertenciam ao sorogrupo 1 , principalmente sorotipo $1 / 2$ c, e $28,2 \%$ ao sorotipo 4 , principalmente $4 \mathrm{~b}$. Ainda segundo estes autores, os casos clínicos observados em Navarra, no mesmo período do experimento, eram ocasionados principalmente pelo sorotipo 4b. Fantelli \& Stephan (2001) obtiveram resultados semelhantes aos de Vitas et al. (2004), isolando maior quantidade do sorotipo $1(76,7 \%)$ do que do sorotipo $4 \mathrm{~b}(23,25 \%)$.

Metades das amostras de carnes bovinas moídas analisadas apresentaram-se contaminadas por bactérias do gênero Listeria, sendo que, em duas destas observouse a presença de L. monocytogenes. No Brasil, não há um limite específico para L. monocytogenes estipulado para carne moída crua, entretanto, de acordo com a Resolução RDC n ${ }^{\circ} 12$ (BRASIL, 2001), são considerados produtos em condições sanitárias insatisfatórias aqueles cujos resultados analíticos estão acima dos limites estabelecidos para amostra indicativa ou amostra representativa, ou aqueles cujos resultados analíticos demonstram a presença ou a quantificação de outros microrganismos patogênicos ou toxinas que representem risco à saúde do consumidor. Estas duas amostras são, portanto, consideradas impróprias para o consumo segundo a legislação vigente, por 
veicularem um patógeno causador de enfermidades transmitidas por alimentos. O sorotipo 4 b de $L$. monocytogenes foi isolado de uma das amostras analisadas, sendo o mais comumente associado a surtos de listeriose de origem alimentar, mas também houve isolamento do sorotipo $1 / 2 \mathrm{c}$. Estes achados demonstram a necessidade da melhoria das condições higiênicosanitárias dos estabelecimentos varejistas de Niterói, RJ e a importância da utilização do tratamento térmico adequado, para a obtenção de um alimento que não apresente riscos à saúde do consumidor.

\section{REFERÊNCIAS BIBLIOGRÁFICAS}

ACHA, P. N.; SZYFRES, B. Bacterioses y micosis. In: Zoonosis y enfermidades transmisbles communes al hombre y a los animales. 3. ed. Washington: OPS, 2001. v. 1.

BRASIL. Ministério da Saúde. Agência Nacional de Vigilância Sanitária. Resolução $\operatorname{RDC~}^{\circ}$ 12, de 2 de janeiro de 2001. Aprova o regulamento técnico sobre padrões microbiológicos para alimentos. 2001. Disponível em: <http://e-legis.anvisa.gov.br/leisref/public/ showAct.php?id=144\&word=>. Acesso em: 19 jun. 2005.

CORRÊA, W. M.; CORRÊA, C. N. M. Listeriose. In: Enfermidades infecciosas dos mamíferos domésticos. 2 . ed. Rio de Janeiro: Medsi, 1992. cap. 24, p. 367-373.

DONKER-VOET, J. A serological study on some strains of Listeria monocytogenes isolated in Michigan. American Journal of Veterinary Research, [S.1.], v. 20, p. 176-179, 1959.

FANTELLI, K.; STEPHAN, R. Prevalence and characteristics of shigatoxin-producing Escherichia coli and Listeria monocytogenes strains isolated from minced meat in Switzerland. International Journal Food Microbiology, Amsterdam, v. 70, n. 1/2, p. 63-69, 2001 .

JAY, J. M. Listerioses de origem animal. In:

Microbiologia de alimentos. 6. ed. Porto Alegre: Artmed, 2005. cap. 25, p. 517-542, 711 p.

JAWETZ, E.; MELNICK, J. L.; ADELBERG, E. A. Microbiologia médica. 20. ed. Rio de Janeiro: Guanabara Koogan, 1998. 524 p.
KAMAT, A. S.; NAIR, P. M. Identification of Listeria innocua as a Biological indicator for inactivation of $L$. monocytogenes by some meat processing treatments. Lebensm-Wissu-Technology, London, v. 29, p. 714-720, 1996.

KASNOWSKI, M. C. Listeria spp., Escherichia coli: isolamento, identificação, estudo sorológico e antimicrobiano em corte de carne bovina (alcatra) inteira e moída. 2004. 110 f. Dissertação (Mestrado em Higiene Veterinária e Processamento Tecnológico de Produtos de Origem Animal) - Universidade Federal Fluminense, Niterói, 2004.

LUND, A. M.; ZOTTOLA, E. A.; PUSCH, D. J. Comparison of methods for isolation of Listeria from raw-milk. Journal of Food Protection, Des Moines, v. 54, n. 8, p. 602-606, 1991.

MARTH, E. H. Disease characteristic of Listeria monocytogenes. Food Technology, Oxford, v. 42, n. 51, p. 165-168, 1988.

MCCLAIN, D.; LEE, W. H. Development of USDA-FSIS method for isolation of Listeria monocytogenes from raw meat and poultry. 4. ed. Virginia: Food and Drug Administration, 1984.

MENA, C. et al. Incidence of Listeria monocytogenes in different food products commercialized in Portugal. Food Microbiology, Amsterdam, v. 21, p. 213-216, 2004.

MURRAY, E. G. D.; WEBB, R. A.; SWANN, M. B. R. A disease of rabbits characterized by a large mononuclear leucocytosis, caused by a hitherto undescribed bacillus Bacterium monocytogenes ( $\mathrm{n}$. sp.). Journal Pathology Bacteriology, [S.1.], v. 29, p. 407-439, 1926.

MURRAY, P. R. et al. Listeria, Erysipelothrix e outros bacilos Gram-positivos. In: Microbiologia médica. 3. ed. Rio de Janeiro: Guanabara Koogan, 2000. cap. 27, p. 181-184.

PETRAN, R. L.; SWANSON, K. M. J. Simultaneous Growth of Listeria monocytogenes and Listeria innocua. Journal of Food Protection, Des Moines, v. 56, n. 7, p. 616-618, 1993. 
PIRIE, J. H. H. The genus Listerella. Pirie Science, [S.I.], v. 91, p. $383,1940$.

ROCOURT, J.; GRIMONT, P. A. D. Listeria welshimeri sp. Nov. and Listeria seeligeri sp. nov. International Journal Systematic Bacteriology, Madison, v. 33, p. 866-869, 1983.

SAMADPOUR, M. et al. Incidence of enterohemorrhagic Escherichia coli, Escherichia coli $\mathrm{O} 157$, Salmonella, and Listeria monocytogenes in retail fresh ground beef, sprouts, and mushrooms. Journal of Food Protection, Des Moines, v. 69, n. 2, p. 441-443, 2006.

SEELIGER, H. P. H.; HÖHNE, K. Serotyping of Listeria monocytogenes and related species. Methods Microbiology, [S.1.], v. 13, p. 31-49, 1979.

SEELIGER, H. P. R.; JONES, D. Genus Listeria. In: SNEATH, P. H. A.; MAIR, N. S.; SHAPE, M. E. Bergey's manual of sistematic bacteriology. 9. ed. Baltimore: Willians \& Wilkins, 1996. v. 2, p. 1235-1245.

SEELIGER, H. P. R.; ROCOURT, J.; SCHRETTENBRUNNER, A.; GRIMONT, P. A. D.; JONES, D. Description of Listeria ivanovii sp. nov. International Journal Systematic Bacteriology, Madison, v. 34, p. 336337, 1984.

SEELIGER, H. P. R.; SCOOFS, M. Serological analysis of non-hemolyzing Listeria-strains belonging to a species different from Listeria monocytogenes. In: PROBLEMS OF LISTERIOSIS, INTERNATIONAL SYMPOSIUM, 7., 1979, Varna. Proceedings... Sofia: National Agroindustrial Unions, 1979. p. 24-28.

SILVA, M. C. C. Ocorrência de listeria spp. em embutidos cárneos artesanais comercializados no mercado varejista da cidade de Contagem, MG. 1996. 76 f. Dissertação (Mestrado em Medicina Veterinária) Universidade Federal de Minas Gerais, Belo Horizonte, 1996.

SIRELI, U. T.; EROL, I. Detection of Listeriaspecies in minced beef. Turkish Journal of Veterinary \& Animal Sciences, [S.1.], v. 23, p. 373-380, 1999. Supplement 2.

VITAS, A. I.; AGUADO, V.; GARCIA-JALON, I. Occurrence of Listeria monocytogenes in fresh and processed foods in Navarra (Spain). International Journal of Food Microbiology, Madison, v. 90, p. 349356, 2004

YUCEL, N.; CITAK, S.; GUNDOGAN, N. The incidence of Listeria monocytogenes in raw meat. Indian Veterinary Journal, [S.1.], v. 81, n. 11, p. 1192-1194, 2004.

YUCEL, N.; CITAK, S.; ONDER, M. Prevalence and antibiotic resistance of Listeria species in meat products in Ankara, Turkey. Food Microbiology, Amsterdam, v. 22, p. 2-3, 2005 . 